\title{
Safety of Ocrelizumab in Patients With Relapsing and Primary Progressive Multiple Sclerosis
}

Stephen L. Hauser, MD, Ludwig Kappos, MD, Xavier Montalban, MD, PhD, MBA, Licinio Craveiro, MD, PhD, Cathy Chognot, PhD, Richard Hughes, MD, Harold Koendgen, MD, PhD, Noemi Pasquarelli, PhD, MSc, Ashish Pradhan, MD, Kalpesh Prajapati, MSc, MPhil, and Jerry S. Wolinsky, MD

Neurology ${ }^{\circledR}$ 2021;97:e1546-e1559. doi:10.1212/WNL.0000000000012700

\section{Abstract}

\section{Background and Objectives}

To report safety of ocrelizumab (OCR) up to 7 years in patients with relapsing multiple sclerosis (RMS) and primary progressive multiple sclerosis (PPMS) enrolled in clinical trials or treated in real-world postmarketing settings.

\section{Methods}

Safety analyses are based on integrated clinical and laboratory data for all patients who received OCR in 11 clinical trials, including the controlled treatment and open-label extension (OLE) periods of the phase 2 and 3 trials, plus the phase $3 \mathrm{~b}$ trials VELOCE, CHORDS, CASTING, OBOE, ENSEMBLE, CONSONANCE, and LIBERTO. For selected adverse events (AEs), additional postmarketing data were used. Incidence rates of serious infections (SIs) and malignancies were contextualized using multiple epidemiologic sources.

\section{Results}

At data cutoff (January 2020), 5,680 patients with multiple sclerosis (MS) received OCR $(18,218$ patient-years [PY] of exposure) in clinical trials. Rates per $100 \mathrm{PY}$ (95\% confidence interval) of AEs $(248 ; 246-251)$, serious AEs $(7.3 ; 7.0-7.7)$, infusion-related reactions (25.9; 25.1-26.6), and infections $(76.2 ; 74.9-77.4)$ were similar to those within the controlled treatment period of the phase 3 trials. Rates of the most common serious AEs, including SIs $(2.01 ; 1.81-2.23)$ and malignancies $(0.46 ; 0.37-0.57)$, were consistent with the ranges reported in epidemiologic data.

\section{Discussion}

Continuous administration of OCR for up to 7 years in clinical trials, as well as its broader use for more than 3 years in the real-world setting, are associated with a favorable and manageable safety profile, without emerging safety concerns, in a heterogeneous MS population.

\section{Classification of Evidence}

This analysis provides Class III evidence that long-term, continuous treatment with OCR has a consistent and favorable safety profile in patients with RMS and PPMS. This study is rated Class III because of the use of OLE data and historical controls.

\author{
Correspondence \\ Dr. Hauser \\ stephen.hauser@ucsf.edu
}

\section{RELATED ARTICLE}

Editorial

Longer-term Safety of

B-Cell Therapy With

Ocrelizumab in Multiple

Sclerosis

Page 751

\section{MORE ONLINE}

(II) Class of Evidence Criteria for rating

therapeutic and diagnostic studies

NPub.org/coe 


\section{Glossary}

$\mathbf{A E}=$ adverse event $\mathbf{A L C}=$ absolute lymphocyte count $\mathbf{A N C}=$ absolute neutrophil count $\mathbf{B L}=$ baseline $\mathbf{C I}=$ confidence interval; CTP = controlled treatment period; DMT = disease-modifying treatment; ER = estrogen receptor; IFN = interferon; Ig = immunoglobulin; IRR = infusion-related reaction; LLN = lower limit of normal; $\mathbf{M S}=$ multiple sclerosis; $\mathbf{N K}=$ natural killer; $\mathbf{N M S C}=$ nonmelanoma skin cancer; $\mathbf{O C R}=$ ocrelizumab; OLE = open-label extension; PML = progressive multifocal leukoencephalopathy; PPMS = primary progressive multiple sclerosis; PR = progesterone receptor; PwMS = patients with multiple sclerosis; PY = patient-years; RMS = relapsing multiple sclerosis; SAE = serious adverse event; SEER = Surveillance, Epidemiology, and End Results; SI = serious infection; SIR = standardized incidence ratio; UTI = urinary tract infection; W12 = week 12.

Ocrelizumab (OCR) is a recombinant humanized monoclonal antibody that selectively depletes CD20-expressing B cells, while preserving the capacity for B-cell reconstitution and preexisting humoral immunity. ${ }^{1,2}$ The safety and efficacy of OCR were characterized in phase 2 and 3 studies, leading to the approval of OCR for the treatment of patients with relapsing multiple sclerosis (RMS) and primary progressive multiple sclerosis (PPMS). ${ }^{3-5}$ Results from these trials showed that OCR was associated with near-complete suppression of new brain MRI activity, significant reduction in disability progression compared with interferon (IFN)- $\beta$-1a or placebo, and significantly lower relapse activity compared with IFN- $\beta-1 \mathrm{a} .^{3-5}$ The clinical benefits of OCR were shown to be sustained over a follow-up period of up to 7 years, with more favorable disability outcomes in patients initiating OCR treatment earlier. ${ }^{6,7}$

In controlled treatment periods (CTPs) of the pivotal phase 3 trials, infusion-related reactions (IRRs), respiratory tract infections, and urinary tract infections (UTIs) were the most common adverse events (AEs) associated with $\mathrm{OCR}^{4,5,8}$ A numerical imbalance of malignancies was observed in patients treated with OCR relative to its comparators, mostly driven by a higher rate of breast cancer; overall, these events were uncommon. ${ }^{4,5}$ Safety surveillance to understand the long-term benefit-risk profile of OCR in patients with MS (PwMS) is therefore warranted.

Here we provide an integrated safety analysis of PwMS treated with OCR in 11 clinical trials as of January 2020, over a period of up to 7 years, and report assessments of special interest from global postmarketing surveillance.

\section{Methods}

\section{Trial Design, OCR Exposure, and Data Cutoff}

Safety analyses are based on integrated data from all PwMS who received OCR during the controlled treatment and associated open-label extension (OLE) periods of the phase 2 and 3 clinical trials, plus 7 phase $3 \mathrm{~b}$ trials (Figure 1). Details on study methodologies and designs are presented in the Supplemental Material and eTable 1 (available from Dryad, doi.org/10.5061/dryad.w3r2280qn).

Clinical trial exposure was determined for patients who received at least one dose of OCR. Exposure time included both time on OCR treatment and subsequent off-treatment (safety follow-up) up to January 3, 2020. The term "OCR all-exposure" describes the overall clinical trial patient population, whereas "phase 3 CTP+OLE" refers to the patient population from the pivotal phase 3 trials (OPERA 1, OPERA 2, and ORATORIO) and respective OLEs (Figure 1). The cutoff date for postmarketing data was July 31, 2020 (fatalities, progressive multifocal leukoencephalopathy [PML], and female breast cancer).

\section{Clinical and Laboratory Safety Assessments and Statistical Analysis}

Safety outcomes including AEs, serious AEs (SAEs), and AEs leading to treatment discontinuation were monitored and coded as per Medical Dictionary for Regulatory Activities (versions 18.0 to 22.1). Standard criteria for determining seriousness and severity were used. To account for different exposure lengths, rates of AEs per 100 patient-years (PY) are presented. Multiple occurrences of the same $\mathrm{AE}$ in 1 patient were counted multiple times, except for malignancies. Calculation of $95 \%$ confidence intervals (CIs) used an exact method based on the Poisson distribution. For further details on clinical and laboratory safety assessments, see the Supplemental Material (available from Dryad, doi.org/10.5061/dryad.w3r2280qn).

\section{Standard Protocol Approvals, Registrations, and Patient Consents}

The protocols (ClinicalTrials.gov identifier numbers NCT00676715, NCT01247324, NCT01412333, NCT01194570, NCT02545868, NCT02637856, NCT02861014, NCT02688985, NCT03085810, NCT03523858, and NCT03599245) were approved by relevant institutional review boards/ethics committees. All patients provided written informed consent.

\section{Classification of Evidence}

This analysis provides Class III evidence that long-term, continuous treatment with OCR has a consistent and favorable safety profile in patients with RMS and PPMS. This study is rated Class III because of the use of OLE data and historical controls.

\section{Data Availability}

Individual patient-level data are available to qualified researchers. For full details on governing policies and procedures to request access, see the Supplemental Material (available from Dryad, doi.org/10.5061/dryad.w3r2280qn). 


\section{Results}

\section{Patient Population and Treatment Exposure}

As of January 2020, 5,680 PwMS (RMS 4,376; PPMS 1,304), with a median (range) age of $38.0(18-66)$ years at start of treatment, had received OCR across multiple clinical trials, resulting in 18,218 PY of exposure (Figure 1). Of these, 2,092 PwMS had received OCR in the pivotal phase 3 trials (median [range] age at start of treatment: RMS 38.0 [18-58] years; PPMS 47.0 [20-59] years), accounting for 11,424 PY of exposure over a period of up to 7 years. In the all-exposure population, $>50 \%$ of patients had received $\geq 5$ doses of OCR and $28 \%$ of patients had received $\geq 10$ doses of OCR. The total patient exposure in PY for each trial is presented in Figure 1. As of July 31, 2020, an estimated 174,508 PwMS have started OCR globally, of which 167,684 initiated OCR in the postmarketing experience, amounting to an estimated exposure of 249,971 PY.

\section{Overview of AEs}

\section{All AEs and SAEs}

Cumulative rates of AEs (248 per 100 PY; 95\% CI 246-251) and SAEs (7.3 per 100 PY; 95\% CI 7.0-7.7) in all patients with RMS or PPMS $(\mathrm{N}=5,680)$ exposed to OCR over a period of up to 7 years remained consistent with the rates observed during the CTPs of the phase 3 trials (Table 1).

\section{Treatment Discontinuation Due to AEs}

The proportion of patients discontinuing treatment due to AEs over a period of up to 7 years was 3.19\% $(n=181 / 5,680$ patients). For patients treated with either placebo or IFN$\beta-1 \mathrm{a}$, rates were $3.35 \%$ and $6.17 \%$, respectively, over a period of up to 3 years during the CTP. Malignancies $(n=40$, mandatory discontinuation), IRRs ( $\mathrm{n}=33$ ) mostly occurring at the first infusion, and infections ( $\mathrm{n}=27$, majority nonserious) were the most common AEs leading to discontinuation in the OCR all-exposure population (available from Dryad, eTable 2, doi.org/10.5061/dryad.w3r2280qn).

\section{Fatal Outcomes}

As of January 2020, 26 fatal outcomes (RMS 11/4,376; PPMS $15 / 1,304)$ had been reported in the OCR all-exposure population in clinical trials, a rate of 0.14 per $100 \mathrm{PY}(95 \% \mathrm{CI}$ $0.09-0.21$ ) (Table 1). This is consistent with the rate observed at the end of the CTP and similar to rates observed for comparators (Table 1). The most frequent causes of fatal outcomes

Figure 1 Safety Analyses Populations: Clinical Trials Overview and Patient Exposure as of January 2020

A. Clinical trials overview and patient exposure

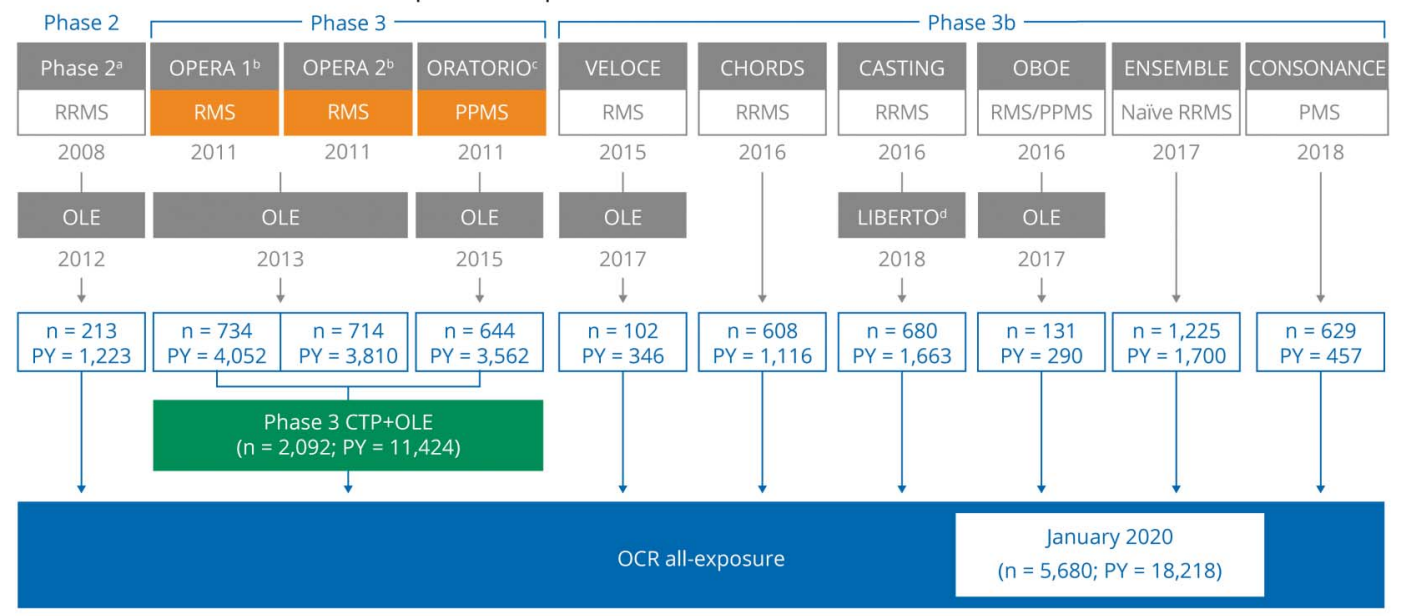

B. Populations used in the analysis to report different clinical and laboratory safety assessments

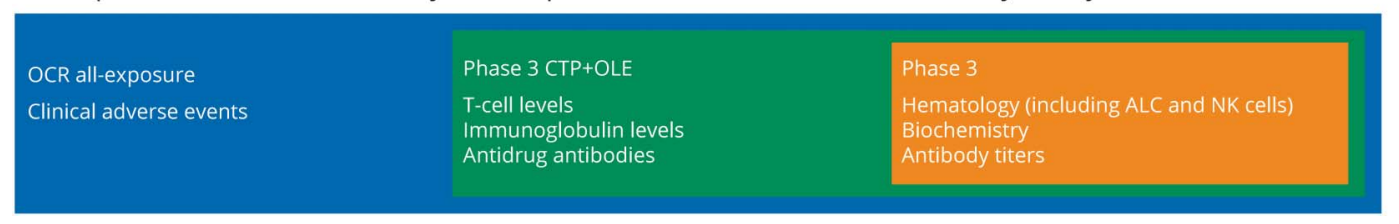

(A) Clinical trials overview and patient exposure. (B) Populations used in the analysis to report different clinical and laboratory safety assessments. Data cutoff: January 2020. Patients received ocrelizumab (OCR) $600 \mathrm{mg}$ by IV infusion every 24 weeks, with the first dose split into two 300 mg infusions given 14 days apart. The exceptions were the controlled treatment period (CTP) of ORATORIO, where all doses were given as split 300 mg infusions, and the phase 2 trial, where in 1 treatment arm the first dose was split into two 1,000 mg infusions administered 14 days apart followed by another 1,000 mg dose at week 24 . Prior to each infusion, patients were pretreated with IV $100 \mathrm{mg}$ methylprednisolone (or equivalent), an IV or oral antihistamine, and an optional analgesic/antipyretic. The term “OCR allexposure" is used to describe the overall clinical trial patient population, whereas the term "phase 3 CTP + open-label extension (OLE)" refers to the patient population from the pivotal phase 3 trials (OPERA 1, OPERA 2, and ORATORIO) and respective OLEs. Boxes are color-coded according to the populations used for

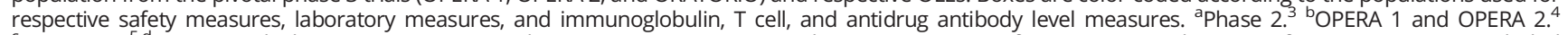
'ORATORIO. ${ }^{5}$ dLIBERTO is the long-term extension study to CASTING, ENSEMBLE, and CONSONANCE. As of January 2020 , only patients from CASTING were included in LIBERTO ( $=$ = 439; patient-years [PY] = 1,155). ALC = absolute lymphocyte count; CTP = controlled treatment period; NK = natural killer; PMS = progressive multiple sclerosis; PPMS = primary progressive multiple sclerosis; RMS = relapsing multiple sclerosis; RRMS = relapsing-remitting multiple sclerosis. 
Table 1 Rates per 100 Patient-Years (PY) of Adverse Events (AEs) in the Pivotal Phase 3 Controlled Treatment Period (CTP) + Open-Label Extension (OLE) and All-Exposure Populations

\begin{tabular}{|c|c|c|c|c|c|c|c|}
\hline \multirow[b]{3}{*}{$\mathrm{AE}$, rate per $100 \mathrm{PY}(95 \% \mathrm{Cl})$} & \multicolumn{3}{|l|}{ OPERA } & \multicolumn{3}{|l|}{ ORATORIO } & \\
\hline & \multicolumn{2}{|l|}{ Стра } & \multirow{2}{*}{$\begin{array}{l}\text { CTP+OLE }^{b} \\
O C R \\
(N=1,448 ; 7,862 P Y)\end{array}$} & \multicolumn{2}{|l|}{ СтP ${ }^{a}$} & \multicolumn{2}{|l|}{$C T P+O L E^{b}$} \\
\hline & $\begin{array}{l}\text { IFN- } \beta-1 \mathrm{a} \\
(\mathrm{n}=826 ; 1,399 \mathrm{PY})\end{array}$ & $\begin{array}{l}\text { OCR } \\
(n=825 ; 1,448 \text { PY) }\end{array}$ & & $\begin{array}{l}\text { Placebo } \\
\text { (n = 239; } 729 \text { PY) }\end{array}$ & $\begin{array}{l}\text { OCR } \\
(n=486 ; 1,606 \text { PY) }\end{array}$ & $\begin{array}{l}\text { OCR } \\
(\mathrm{N}=644 ; 3,562 \mathrm{PY})\end{array}$ & $\begin{array}{l}\text { OCR all-exposure }{ }^{c} \\
(\mathrm{~N}=5,680 ; 18,218 \mathrm{PY})\end{array}$ \\
\hline Any AEs & $296(287-305)$ & $290(281-299)$ & 206 (203-209) & $259(247-271)$ & $252(244-260)$ & $237(232-242)$ & $248(246-251)$ \\
\hline AEs leading to discontinuation & $3.93(2.96-5.12)$ & $2.35(1.63-3.28)$ & $1.25(1.01-1.52)$ & $1.10(0.47-2.16)$ & $1.25(0.76-1.92)$ & $1.07(0.76-1.46)$ & $1.06(0.92-1.22)$ \\
\hline Infusion-related reaction & NA & $0.76(0.38-1.36)$ & $0.27(0.17-0.41)$ & $0.14(0.00-0.76)$ & $0.13(0.02-0.45)$ & $0.06(0.00-0.21)$ & $0.19(0.13-0.26)$ \\
\hline Malignancies & $0.07(0.00-0.40)$ & $0.07(0.00-0.39)$ & $0.19(0.11-0.32)$ & $0.14(0.00-0.76)$ & $0.44(0.18-0.90)$ & $0.42(0.24-0.70)$ & $0.22(0.16-0.30)$ \\
\hline Infections and infestations & NA & $0.14(0.02-0.50)$ & $0.20(0.12-0.33)$ & $0.41(0.09-1.20)$ & $0.25(0.07-0.64)$ & $0.20(0.08-0.41)$ & $0.16(0.11-0.23)$ \\
\hline Serious AEs & $6.3(5.1-7.8)$ & $5.4(4.3-6.7)$ & $5.9(5.4-6.5)$ & $12.1(9.7-14.9)$ & $10.2(8.7-11.8)$ & $12.9(11.8-14.2)$ & $7.3(7.0-7.7)$ \\
\hline Malignancies ${ }^{\mathrm{d}, \mathrm{e}}$ & $0.14(0.02-0.52)$ & $0.28(0.08-0.71)$ & $0.36(0.24-0.52)$ & $0.27(0.03-0.99)$ & $0.93(0.52-1.54)$ & $1.00(0.70-1.39)$ & $0.46(0.37-0.57)$ \\
\hline Fatal outcomes & $0.14(0.02-0.52)$ & $0.07(0.00-0.38)$ & $0.05(0.01-0.13)$ & $0.41(0.08-1.20)$ & $0.25(0.07-0.64)$ & $0.39(0.22-0.66)$ & $0.14(0.09-0.21)$ \\
\hline Infections and infestations & $67.8(63.5-72.2)$ & $84.5(79.9-89.4)$ & $72.2(70.3-74.1)$ & $72.5(66.5-79.0)$ & $70.8(66.8-75.0)$ & $74.2(71.4-77.1)$ & $76.2(74.9-77.4)$ \\
\hline Urinary tract infection & $9.7(8.1-11.4)$ & $11.6(9.9-13.5)$ & $11.5(10.7-12.2)$ & $17.8(14.9-21.2)$ & $15.1(13.2-17.1)$ & $19.0(17.6-20.5)$ & $12.4(11.9-13.0)$ \\
\hline Nasopharyngitis & $8.3(6.9-9.9)$ & $13.0(11.2-15.0)$ & $10.3(9.6-11.1)$ & $17.7(14.8-21.0)$ & $12.8(11.1-14.6)$ & $12.4(11.3-13.6)$ & $13.4(12.8-13.9)$ \\
\hline Upper respiratory tract infection & $9.4(7.8-11.1)$ & $13.3(11.5-15.3)$ & $12.2(11.4-13.0)$ & $2.9(1.8-4.4)$ & $5.2(4.2-6.5)$ & $5.1(4.4-5.9)$ & $9.7(9.3-10.2)$ \\
\hline Bronchitis & $2.2(1.5-3.1)$ & $3.5(2.6-4.6)$ & $3.7(3.3-4.1)$ & $2.9(1.8-4.4)$ & $2.6(1.9-3.5)$ & $2.8(2.2-3.4)$ & $3.2(2.9-3.4)$ \\
\hline Influenza & $3.3(2.4-4.4)$ & $3.1(2.3-4.2)$ & $2.5(2.2-2.9)$ & $3.4(2.2-5.1)$ & $4.6(3.6-5.7)$ & $4.0(3.4-4.7)$ & $3.7(3.5-4.0)$ \\
\hline Serious infections ${ }^{f}$ & $1.79(1.16-2.64)$ & $0.83(0.43-1.45)$ & $1.32(1.08-1.60)$ & $3.02(1.89-4.57)$ & $2.74(1.99-3.68)$ & $4.41(3.75-5.15)$ & $2.01(1.81-2.23)$ \\
\hline Pneumonia & $0.14(0.02-0.52)$ & $0.07(0.00-0.39)$ & $0.25(0.16-0.39)$ & $0.41(0.09-1.20)$ & $0.50(0.22-0.98)$ & $0.59(0.37-0.90)$ & $0.30(0.22-0.39)$ \\
\hline Urinary tract infection & $0.14(0.02-0.52)$ & NA & $0.10(0.04-0.20)$ & $0.69(0.22-1.60)$ & $0.25(0.07-0.64)$ & $0.90(0.61-1.27)$ & $0.30(0.23-0.39)$ \\
\hline Cellulitis & $0.07(0.00-0.40)$ & $0.14(0.02-0.50)$ & $0.05(0.01-0.13)$ & NA & $0.19(0.04-0.55)$ & $0.45(0.26-0.73)$ & $0.14(0.09-0.21)$ \\
\hline Injury, poisoning, and procedural complications & $17.1(15.0-19.4)$ & $45.9(42.4-49.5)$ & $24.1(23.1-25.3)$ & $36.3(32.1-41.0)$ & $43.5(40.3-46.8)$ & $33.7(31.8-35.7)$ & $37.0(36.1-37.9)$ \\
\hline Infusion-related reaction & $7.9(6.5-9.5)$ & $34.9(31.9-38.1)$ & $14.3(13.5-15.1)$ & $20.3(17.2-23.8)$ & $31.0(28.3-33.9)$ & $20.3(18.9-21.9)$ & $25.9(25.1-26.6)$ \\
\hline
\end{tabular}

Infusion-related reaction

ron; $\mathrm{NA}=$ not available; $\mathrm{OCR}=$ ocrelizumab.

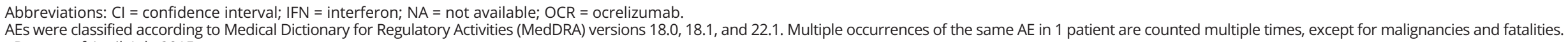
a Data as of April-July 2015.

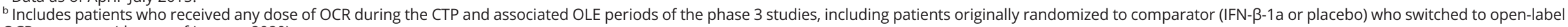
OCR treatment (data as of January 2020).

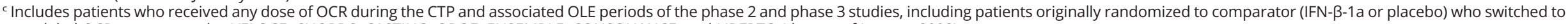
open-label OCR treatment, plus VELOCE, CHORDS, CASTING, OBOE, ENSEMBLE, CONSONANCE, and LIBERTO (data as of January 2020).

"Malignancies are identified using AEs falling into the standard MedDRA query "Malignant tumors (narrow)."

For malignancies, incidence rates are reported and exposure in PY was calculated from first treatment to onset of first malignancy.

Serious infections are defined using AEs falling into the MedDRA system organ class "Infections and infestations" and using "Is the event nonserious or serious?" from the AE case report form. 
were suicides $(n=7)$, infections $(n=4)$, malignancies $(n=4)$, and cardiac events $(n=3)$. No specific temporal patterns of exposure from first or last dose of OCR were identified.

As of July 31,2020 , the fatality rate (0.28 per 100 PY; 95\% CI 0.26-0.31) from postmarketing sources was slightly higher than that observed in the clinical trial setting.

\section{Infusion-Related Reactions}

IRRs were among the most common AEs reported with OCR in the CTPs of the phase 3 trials. ${ }^{4,5}$ Detailed analyses on IRRs during the CTP were reported previously. ${ }^{9}$ The rate of IRRs in the OCR all-exposure population decreased with subsequent infusions (Table 1 ).

\section{Laboratory Measurements}

\section{Biochemistry}

No drug-induced hepatotoxicity was observed (hepatotoxicity and other abnormalities data are available from Dryad, eTable 3, doi.org/10.5061/dryad.w3r2280qn).

\section{Absolute Lymphocyte Count (T Cells, B Cells, and Natural Killer Cells)}

In patients treated with OCR, the mean absolute lymphocyte count (ALC) decreased by approximately $15 \%$ between baseline (BL) and week 12 (W12) in OPERA 1 (1.86 [BL] to $\left.1.57[\mathrm{~W} 12] \times 10^{9} / \mathrm{L}\right)$, OPERA $2(1.85[\mathrm{BL}]$ to $1.54[\mathrm{~W} 12] \times$ $\left.10^{9} / \mathrm{L}\right)$, and ORATORIO $\left(1.88[\mathrm{BL}]\right.$ to $\left.1.55[\mathrm{~W} 12] \times 10^{9} / \mathrm{L}\right)$ trials. This was likely driven by pharmacodynamic effects of B-cell depletion, as mean/median ALC remained stable thereafter until the end of the CTP (data not shown).

The proportion of patients with episodes of marked lymphopenia $\left(\right.$ ALC $\left.<0.7 \times 10^{9} / \mathrm{L}\right)$ was $5.3 \%$ (OCR) vs $12.8 \%($ IFN- $\beta-1 \mathrm{a})$ in OPERA, and 6.8\% (OCR) vs 5.0\% (placebo) in ORATORIO, but no episodes of ALC $<0.2 \times 10^{9} / \mathrm{L}$ (grade 4) were reported in patients treated with OCR. Most marked lymphopenia episodes were single occurrences (OPERA: 76.4\%; ORATORIO: 71.1\%) that were not sustained or replicated.

\section{T Lymphocytes}

Flow cytometry analyses showed decreases of $\leq 6 \%$ in $\mathrm{CD}^{+}$ T-cell populations by week 2 in OCR-treated patients in the pivotal phase 3 trials. These were likely driven by the reduction in $\mathrm{CD}^{+} \mathrm{T}$-cell levels, because only minimal changes in the $\mathrm{CD}^{+}$T-cell levels were observed throughout the CTPs. During the OLEs of the phase 3 trials, $\mathrm{CD} 3{ }^{+} \mathrm{CD} 4^{+}$and $\mathrm{CD} 3^{+} \mathrm{CD} 8^{+} \mathrm{T}$-cell counts gradually recovered to baseline levels (Figure 2, C and D; eFigure 1 [available from Dryad, doi.org/10.5061/dryad.w3r2280qn]).

\section{Natural Killer Cells}

During the CTP of the pivotal phase 3 trials, treatment with OCR had no impact on natural killer (NK; $\mathrm{CD} 16^{+} \mathrm{CD} 56^{+}$) cell counts, remaining generally similar to levels observed for patients with PPMS in the placebo group (available from Dryad, eTable 4, doi.org/10.5061/dryad.w3r2280qn). In contrast, IFN- $\beta$-1a treatment resulted in decreases in NK cell counts up to week 96.

\section{Absolute Neutrophil Count}

Throughout the CTP of the pivotal phase 3 trials, mean neutrophil levels remained above lower limit of normal (LLN) and stable. The proportion of patients with marked neutropenia, defined as absolute neutrophil count (ANC) $<1.5 \times 10^{9} / \mathrm{L}$, was $4.4 \%$ (OCR) vs $18.2 \%$ (IFN- $\left.\beta-1 \mathrm{a}\right)$ in OPERA and $4.6 \%$ (OCR) vs $1.7 \%$ (placebo) in ORATORIO. Most marked neutropenia episodes in OCR arms were single occurrences (OPERA: 68.3\%; ORATORIO: 73.1\%) that were not sustained or replicated.

As of January 2020, 9 serious neutropenia cases were reported in the OCR all-exposure population $(n=5,680$ patients; $18,218 \mathrm{PY}$ ). Seven patients were symptomatic with signs suggestive of infection (most commonly pharyngitis), 2 patients were asymptomatic. In 4 cases, neutropenia required specific treatment with a granulocyte-colony stimulating factor (filgrastim). All 9 cases resolved (median [range] 10 [3-61] days) and all patients remained on OCR.

\section{Immunoglobulins}

Over a period of up to 7 years of OCR treatment, there was a mean absolute reduction in serum immunoglobulin $M$ levels of $-0.78 \mathrm{~g} /$ $\mathrm{L}$ (mean relative reduction of 55.8\%) in the OPERA population, characterized by a faster drop in the first year followed by a slower decline (available from Dryad, eFigure 2, doi.org/10.5061/ dryad.w3r2280qn). Serum immunoglobulin G (IgG) levels decreased at an average rate of $-0.33 \mathrm{~g} / \mathrm{L}$ per year $(-2.99 \%$ per year $)$ (Figure 2A). A similar trajectory was observed for immunoglobulin A (IgA) levels (available from Dryad, eFigure 2, doi.org/10.5061/ dryad.w3r2280qn). The temporal evolution for serum immunoglobulin ( $\mathrm{Ig}$ ) in the ORATORIO population was comparable to trajectories observed in OPERA (Figure 2B; eFigure 2 [available from Dryad, doi.org/10.5061/dryad.w3r2280qn]).

\section{Infections}

\section{All Infections}

The overall rate of infections (76.2 per $100 \mathrm{PY}$; 95\% CI 74.9-77.4) in the OCR all-exposure population, over a period of up to 7 years, remained consistent with rates observed during the phase 3 CTPs. During this period, infections were frequently reported in both OCR and comparator groups, with an increased risk of nonserious upper respiratory tract infections (predominantly nasopharyngitis) and UTIs (Table 1). These remained the most common types of infections in the OCR allexposure population over a period of up to 7 years (Table 1).

\section{Serious Infections}

Over a period of up to 7 years, the rates of serious infections (SIs) in the RMS all-exposure and PPMS all-exposure populations fluctuated over time but showed no meaningful year-on-year variation. Among patients with PPMS, the rate of SIs remained higher than in RMS (Figure 3A). The incidence of SIs in the OCR all- 
exposure population over a period of up to 7 years was infrequent, at a rate of 2.01 per $100 \mathrm{PY}$ (95\% CI 1.81-2.23) (Table 1).

The most common SIs in the OCR all-exposure population were UTIs (0.30; 95\% CI 0.23-0.39), pneumonia (0.30; 95\% CI $0.22-0.39)$, and cellulitis (0.14; 95\% CI 0.09-0.21). Serious herpes virus-associated infections were uncommon (multidermatomal herpes zoster, $\mathrm{n}=2$; genital herpes, $\mathrm{n}=2$; herpes simplex, $\mathrm{n}=1$; herpes keratitis, $\mathrm{n}=1 ; 0.03$ per $100 \mathrm{PY}$ [95\% CI 0.01-0.07]; their incidence stable up to 7 years). These patients were hospitalized, no cases were life-threatening, and all resolved within the expected clinical course (12-22 days).

No cases of hepatitis B virus infection reactivation, fever of unknown origin, cryptococcosis, aspergillosis, listeriosis, toxoplasmosis, or cytomegalovirus infection were reported in the OCR all-exposure population.
As of July 31, 2020, no cases of PML were reported in the context of clinical trials. Nine confirmed (definite diagnosis) ${ }^{11}$ cases of PML were reported outside of clinical trials, of which 8 were reported as carryover cases. Additional details have been presented previously ${ }^{12}$ and can be found in eTable 5 (available from Dryad, doi.org/10.5061/dryad.w3r2280qn).

Most SIs resolved without sequelae (93.2\%; 342/367 SIs) within the expected clinical course ( $57.7 \%$ lasted $\leq 14$ days [206/357 resolved SIs]; $79.6 \%$ lasted $\leq 28$ days [284/357 resolved SIs]). Discontinuation of OCR due to SIs was uncommon (14/5,680 [0.25\%] patients).

\section{Association Between SIs and Lymphocyte or Neutrophil Levels}

In the phase 3 CTP+OLE population $(n=2,092$, exposure up to 7 years), no association between low lymphocyte levels

Figure 2 Change in Serum Immunoglobulin G (IgG) Levels and CD3 ${ }^{+}$T-Cell Levels Through Controlled Treatment Period (CTP) and Open-Label Extension (OLE) Period of the Phase 3 Studies

\section{A. OPERA}

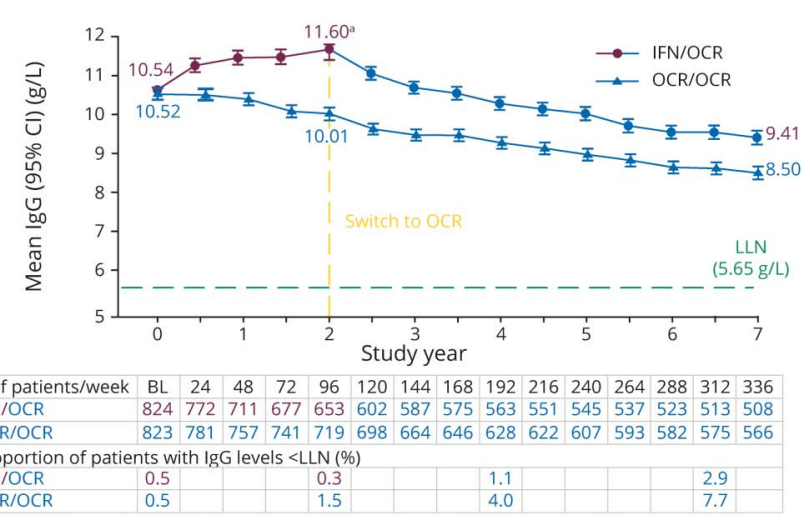

C. OPERA

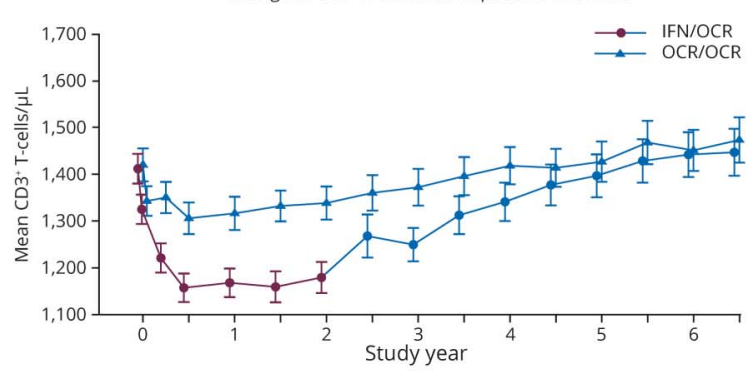

\begin{tabular}{|l|l|l|l|l|l|l|l|l|l|l|l|l|l|l|l|l|}
\hline $\begin{array}{l}\text { \# of patients/ } \\
\text { week }\end{array}$ & $\mathrm{BL}$ & 2 & 12 & 24 & 48 & 72 & 96 & 120 & 144 & 168 & 192 & 216 & 240 & 264 & 288 & 312 \\
\hline
\end{tabular}

\begin{tabular}{|l|l|l|l|l|l|l|l|l|l|l|l|l|l|l|l|l|l|l|l|}
\hline IFN/OCR & 766 & 791 & 771 & 741 & 703 & 658 & 622 & 553 & 560 & 534 & 537 & 523 & 508 & 507 & 504 & 485 \\
\hline
\end{tabular}

\begin{tabular}{|l|l|l|l|l|l|l|l|l|l|l|l|l|l|l|l|l|}
\hline OCR/OCR & 757 & 799 & 765 & 756 & 731 & 726 & 690 & 629 & 628 & 602 & 580 & 573 & 580 & 549 & 563 & 530 \\
\hline
\end{tabular}
B. ORATORIO

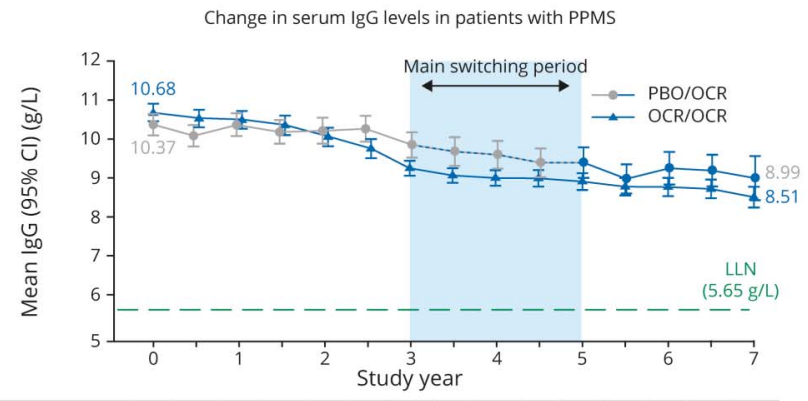

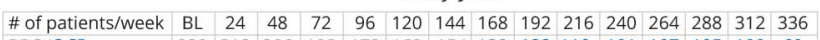

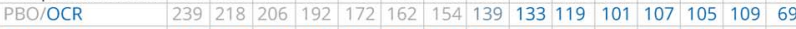
$\begin{array}{llllllllllllllllll}\text { OCR/OCR } & 484 & 430 & 430 & 407 & 402 & 371 & 397 & 384 & 364 & 343 & 330 & 310 & 291 & 276 & 252\end{array}$ Proportion of patients with IgG levels <LLN (\%)

$\mathrm{PBO} / \mathrm{OCR}$ OCR/OCR
D. ORATORIO

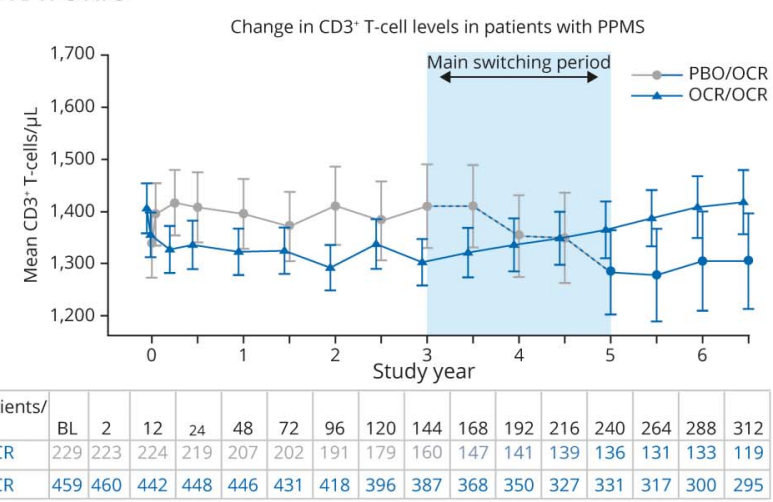

Data cutoff: January 2020. Change in serum levels of IgG from baseline (BL) through the CTP and OLE periods of the pooled OPERA studies (A) and the ORATORIO study (B). Change in CD3 ${ }^{+} T$-cell levels from BL through the CTP and OLE periods of the pooled OPERA studies (C) and the ORATORIO study (D). Data on proportion of patients with immunoglobulin (Ig) levels < lower limit of normal (LLN) shown only until week 312, as data at week 336 are not mature. Data at week 336 on change in T-cell levels are not shown as data are not mature. The proportion of patients randomized to ocrelizumab (OCR) in the OPERA population with IgG levels < LLN was 1.5\% at week $96 \%$ and $7.7 \%$ at week 312 (OCR/OCR data). Similarly, the proportion of patients randomized to OCR in the ORATORIO population with IgG levels < LLN was $1.1 \%$ at week 120 and $5.1 \%$ at week 312 (OCR/OCR data). ${ }^{a}$ In patients treated with interferon (IFN), an increase in serum IgG levels was observed over a 2-year period. This is consistent with previous findings from other groups. ${ }^{10} \mathrm{CD}=\mathrm{cluster}$ of differentiation; $\mathrm{Cl}=$ confidence interval; $\mathrm{PBO}$ = placebo; RMS = relapsing multiple sclerosis. 
Figure 3 Rate of Serious Infections Over 7 years and Association With Immunoglobulin Levels

A. Yearly rates of serious infections in the RMS all-exposure and PPMS all-exposure populations

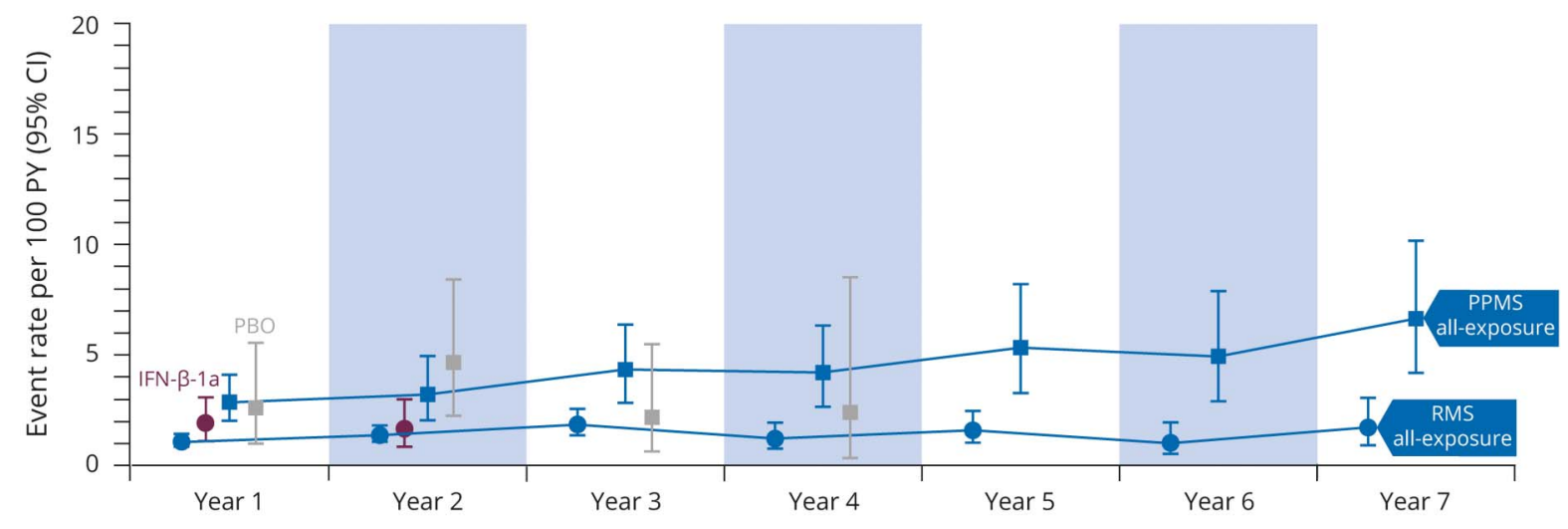

\begin{tabular}{|l|l|c|c|c|c|c|c|}
\hline $\begin{array}{l}\text { PPMS all- } \\
\text { exposure (PY) }\end{array}$ & OCR & 1,106 & 649 & 578 & 525 & 375 & 345 \\
\hline $\begin{array}{l}\text { RMS all- } \\
\text { exposure (PY) }\end{array}$ & OCR & 4,173 & 3,473 & 1,977 & 1,391 & 1,248 \\
\hline OPERA (PY) & IFN- $\beta-1 a$ & 793 & 606 & & 870 \\
\hline ORATORIO (PY) & PBO & 235 & 217 & 186 & 85 & \\
\hline
\end{tabular}

B. Rates of serious infections associated with Ig values above or below the LLN in the phase 3 CTP+OLE population (OPERA and ORATORIO)

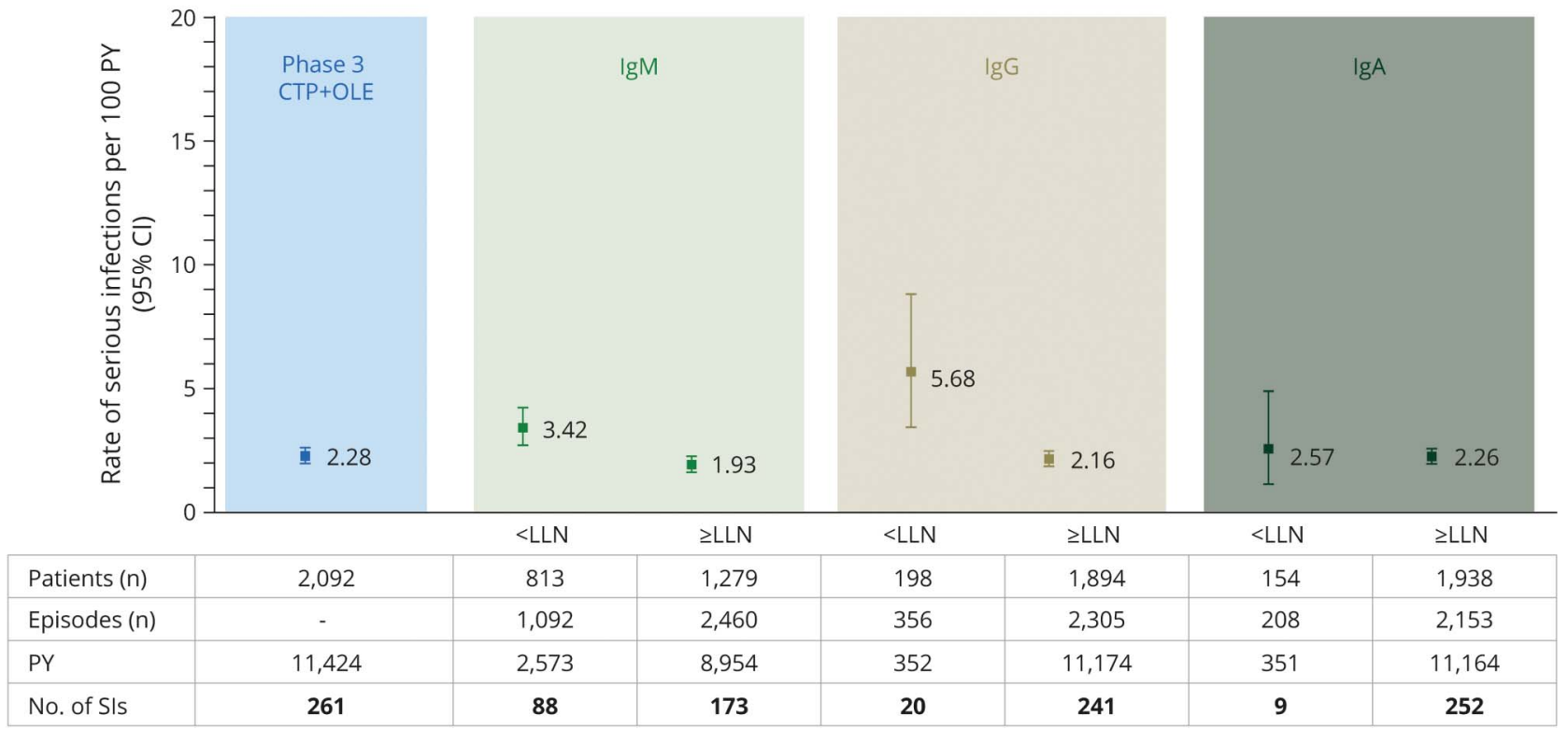

Data cutoff: January 2020. (A) Yearly rates of serious infections (SIs) in patients with relapsing multiple sclerosis (RMS) or primary progressive multiple sclerosis (PPMS) treated with ocrelizumab (OCR) for a period of up to 7 years, during the controlled treatment period (CTP) and associated open-label extension (OLE) periods of the phase 2 and phase 3 studies, including patients originally randomized to comparator (interferon [IFN]- $\beta-1$ a or placebo [PBO]) who switched to open-label OCR treatment, plus VELOCE, CHORDS, CASTING, OBOE, ENSEMBLE, CONSONANCE (PPMS all-exposure only), and LIBERTO ( $n=5,680 ; 18,218$ patient-years [PY]). Yearly rates of SIs of patients who received PBO (gray) or IFN- $\beta-1$ a (purple) during the CTPs are displayed. Due to the event-driven design of ORATORIO, some patients remained on PBO for up to 4 years. (B) Rates of SIs associated with immunoglobulin G (IgG), immunoglobulin M (IgM), and immunoglobulin A (IgA) values above or below the respective lower limit of normal (LLN) in patients who received any dose of OCR during the CTP and associated OLE periods of the phase 3 trials (OPERA 1, OPERA 2, and ORATORIO). $\mathrm{Cl}$ = confidence interval.

$\left(\right.$ ALC $\left.<0.91 \times 10^{9} / \mathrm{L}\right)$ and rates of SIs was observed $(3.17$ per 100 PY [95\% CI 1.96-4.84] during episodes of ALC < LLN vs 2.23 per $100 \mathrm{PY}$ [95\% CI 1.95-2.53] during episodes of ALC $\geq$ LLN). No association was observed between low neutrophil levels $\left(\right.$ ANC $\left.<1.96 \times 10^{9} / \mathrm{L}\right)$ and rates of SIs $(2.02$ per $100 \mathrm{PY}$ [95\% CI 0.74-4.39] during episodes of ANC < LLN vs 2.29 per 100 PY [95\% CI 2.02-2.59] during episodes of ANC $\geq$ LLN). 


\section{Association Between SIs and Ig Levels}

In the phase $3 \mathrm{CTP}+\mathrm{OLE}$ population, an association between decreased $\operatorname{IgG}$ levels ( $\operatorname{IgG}<5.65 \mathrm{~g} / \mathrm{L}$ ) and increased rates of SIs was observed (Figure 3B). Among 2,092 patients continuously treated with OCR up to 7 years, $15(0.7 \%)$ patients experienced an SI while IgG $<$ LLN. The type, severity, duration, and outcome of SIs observed during episodes of IgG $<$ LLN ( $n=20$, in 15 patients) were consistent with the overall SIs observed in OCR-treated patients. All events resolved and all patients continued OCR (data available from Dryad, eTable 6, doi.org/10.5061/dryad. w3r2280qn).

\section{Malignancies and Female Breast Cancer}

Over a period of up to 7 years, the crude incidence rate of all malignancies (including nonmelanoma skin cancer [NMSC]) in the OCR all-exposure population was 0.46 per $100 \mathrm{PY}$ (95\% CI $0.37-0.57$ ) (Table 1). Yearly crude incidence rates of all malignancies and female breast cancer fluctuate and do not suggest a causal or time-dependent/cumulative dose-dependent exposure effect (Figure 4, A and B).

Standardization of incidence rates of all malignancies and female breast cancer was also performed (see Supplemental Material, available from Dryad, doi.org/10.5061/dryad. w3r2280qn). Cases of NMSC were excluded from the OCR all-exposure population and the Danish MS registry for comparison with the general US population (Surveillance, Epidemiology, and End Results [SEER] database). Standardized rates of NMSC (0.20 per 100 PY [95\% CI $0.11-0.38]$ ) remained stable and consistent with epidemiologic references (0.19 per 100 PY [95\% CI 0.15-0.24]). ${ }^{13}$

Over a period of up to 7 years, age- and sex-standardized incidence rate of all malignancies (excluding NMSC) was 0.23 per 100 PY (95\% CI 0.15-0.39) and age-standardized incidence rate of female breast cancer was 0.13 per $100 \mathrm{PY}$ (95\% CI 0.08-0.32) in the OCR all-exposure population (Figure 5, $\mathrm{A}$ and $\mathrm{B}$ ). Calculated standardized incidence ratios (SIRs) indicate no significant excess in the incidence of all malignancies in the OCR all-exposure population compared with a typical MS population or the general population (Figure 5A). The SIR for breast cancer indicates no increased risk in women treated with OCR compared with a typical MS population (Danish) and a nonsignificant excess compared with the general population (SEER) (Figure 5B).

In the OCR all-exposure population, the median age at onset of the 21 patients diagnosed with breast cancer was 49 years. Most had a personal or family history of cancer $(n=13 / 21)$ and current or previous smoking history $(n=8 / 21)$. Invasive ductal carcinoma was the most common histologic presentation and most breast cancers were positive for estrogen receptor (ER) and/or progesterone receptor (PR) (ER+ 15/21 patients; ER+ PR+ 13/21 patients), consistent with the known epidemiology of breast cancers ${ }^{14}$ (available from Dryad, eTable 7, doi.org/10.5061/dryad.w3r2280qn).
Outside the clinical trial setting, the age-standardized incidence rate of female breast cancer was 0.07 per $100 \mathrm{PY}$ (95\% CI 0.06-0.09) in the US postmarketing experience (total exposure over 99,200 PY), as of July 31, 2020. There is no indication of an excess in the incidence rate of female breast cancer in women treated with OCR in the US real-world setting compared with the US (SEER) general population (SIR 0.45 [95\% CI 0.38-0.54]).

\section{Humoral Immunity}

The effect of OCR on preexisting humoral immunity to bacterial and viral antigens was assessed during the CTP of the phase 3 trials by measuring changes in specific antibody titers to common viral and bacterial antigens. At the end of the CTP, the proportion of patients with protective titers against mumps, rubella, and varicella zoster viruses was overall unchanged from baseline in both the OPERA and ORATORIO trials (Table 2). Changes from baseline in the antibody titers against Streptococcus pneumoniae were small and consistent with those in comparator groups in both OPERA and ORATORIO (Table 2).

\section{Antidrug Antibodies}

Minimal immunogenicity was observed over a period of 6.5 years, with a total of 24 patients testing positive for treatmentemergent antidrug antibodies (RMS: 1.0\% [14/1,427]; PPMS $1.6 \%$ [10/635]; for more details, see Supplemental Material, available from Dryad, doi.org/10.5061/dryad.w3r2280qn).

\section{Discussion}

The present analysis provides a comprehensive assessment on the long-term safety of PwMS treated continuously with OCR in clinical trials, as well as the broader population treated in the postmarketing setting. The overall rates of AEs and SAEs reported with OCR in the CTP of the phase 3 trials were comparable to those reported for placebo or IFN- $\beta-1$. The OCR safety profile remained stable throughout the OLE of the phase $2 / 3$ trials, and with the use of OCR in a more heterogeneous MS population across 7 additional studies, as well as realworld settings. The low rates of patients discontinuing OCR due to AEs suggest favorable long-term tolerability, which together with its sustained efficacy, contributes to the high persistence observed in real-world cohorts. ${ }^{15-18}$ Fatality rates in the clinical trials remained below those observed in postmarketing settings, as well as the expected fatality rates $(0.37-0.90$ per $100 \mathrm{PY})$ observed in real-world MS cohorts. ${ }^{18,19}$ It should be noted that postmarketing patients tend to have older age, longer disease duration, higher proportion of progressive MS, and a greater number of previous disease-modifying treatments (DMTs) and comorbidities. ${ }^{15}$

Whereas IRRs were among the most frequently reported AEs with OCR, most patients did not experience IRRs, and the majority were mild to moderate, decreased with the number of infusions, and were effectively managed through 
Figure 4 Yearly Crude Incidence Rates of all Malignancies and Female Breast Cancer in Ocrelizumab (OCR) All-Exposure Population

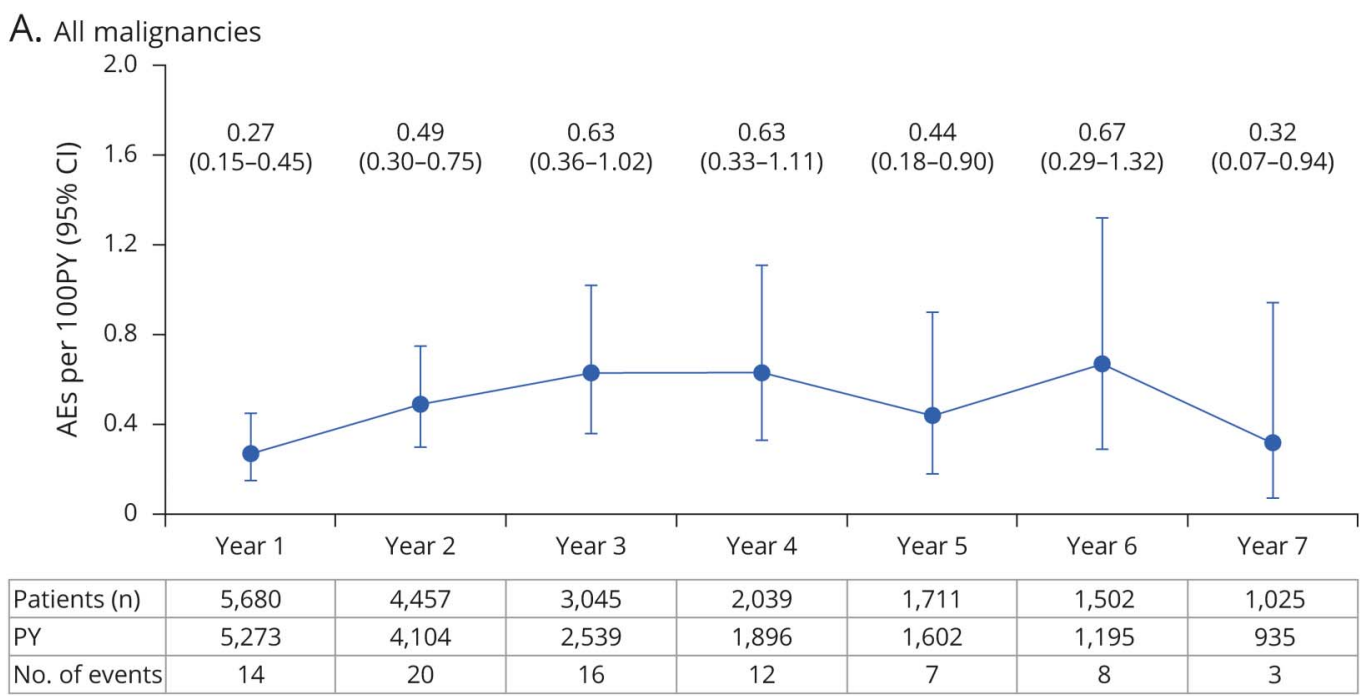

B. Female breast cancer

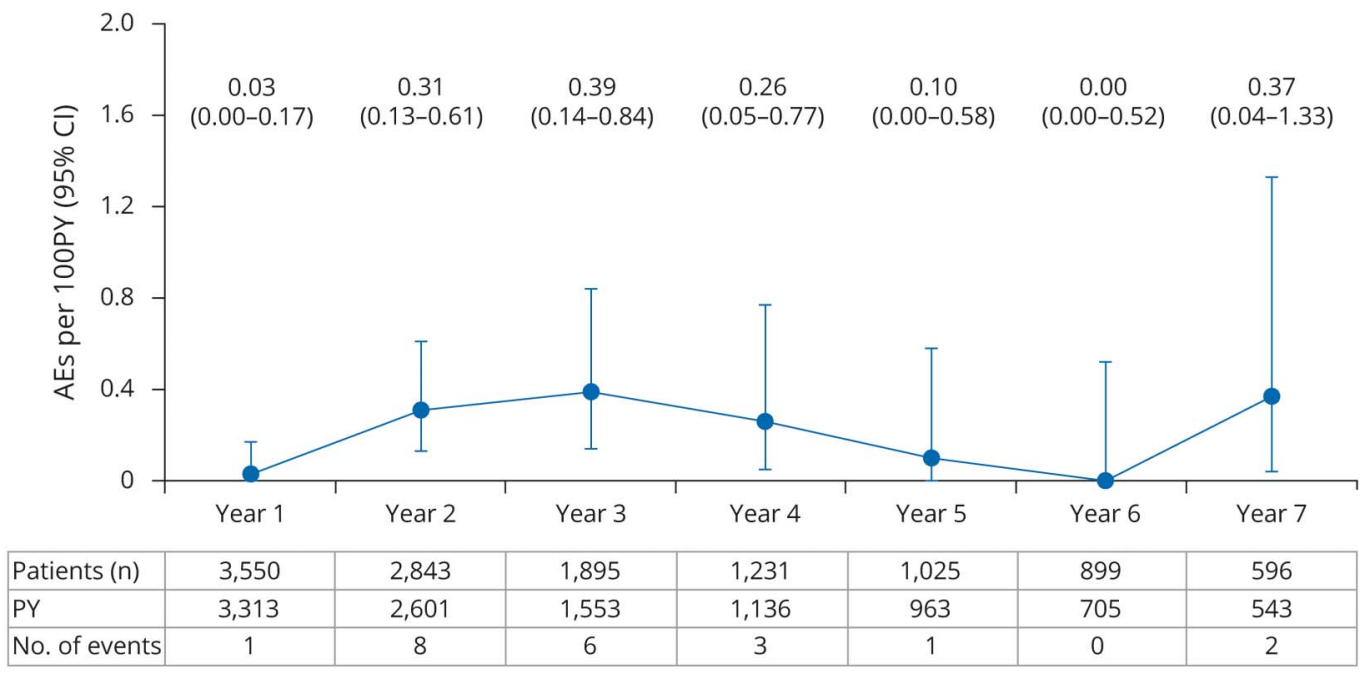

Data cutoff: January 2020. Includes patients who received any dose of OCR during the controlled treatment period (CTP) and associated open-label extension (OLE) periods of the phase 2 and phase 3 studies, including patients originally randomized to comparator (interferon [IFN]- $\beta$-1a or placebo) who switched to open-label OCR treatment, plus VELOCE, CHORDS, CASTING, OBOE, ENSEMBLE, CONSONANCE, and LIBERTO. (A) Crude incidence rates of all malignancies from years 1-7, including nonmelanoma skin cancer (NMSC). Crude incidence rate of all malignancies (including NMSC) in the OCR all-exposure population, as of January 2020: 0.46 (0.37-0.57). (B) Crude incidence rates of female breast cancer from years 1-7. Data on yearly crude incidence rates of all malignancies and female breast cancer shown until year 7 . Year 7 data are not mature due to limited exposure (543 patient-years [PY] for female breast cancer). AE = adverse event; $\mathrm{Cl}$ = confidence interval.

administering premedication, adjustment to infusion rates, and symptomatic treatment. An appropriate premedication protocol with mandatory methylprednisolone and antihistamines, as well as an optional analgesic, was followed. Results from studies investigating a shorter infusion protocol also indicate that reducing infusion duration does not increase the incidence, patterns, or severity of IRRs. ${ }^{20-22}$ This may allow improvements in the overall patient experience and optimization of resources at infusion clinics. ${ }^{23}$

Real-world studies show an increased risk of infection in PwMS relative to non-MS controls, both in treated and un-

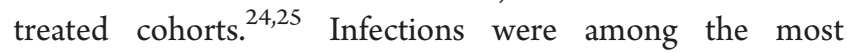

frequently reported AEs in patients treated with OCR However, the rates of SIs were numerically lower in OCRtreated patients compared with controls. Moreover, these rates remained stable with only minimal fluctuation over time in patients with PPMS, and consistent with rates of infectionrelated hospitalizations reported in well-characterized MS registries. ${ }^{26,27}$ UTIs, pneumonia, and cellulitis accounted for the most common SIs, a pattern also observed in real-world MS cohorts, ${ }^{24}$ suggesting that the most common types of SIs in OCR-treated patients do not differ from those expected in PwMS. Herpes was the unique cluster of serious potentially opportunistic infections, but the rates remained infrequent and causal association with OCR was not established. Most 
Figure 5 Cumulative Standardized Incidence Rates of Malignancies and Comparison With Danish Multiple Sclerosis (MS) Registry and Surveillance, Epidemiology, and End Result (SEER) Database

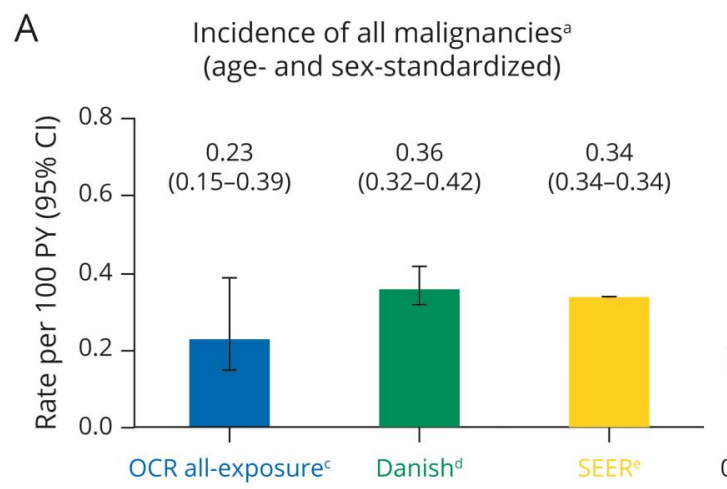

B Incidence of female breast cancer $^{a}$ (age-standardized)

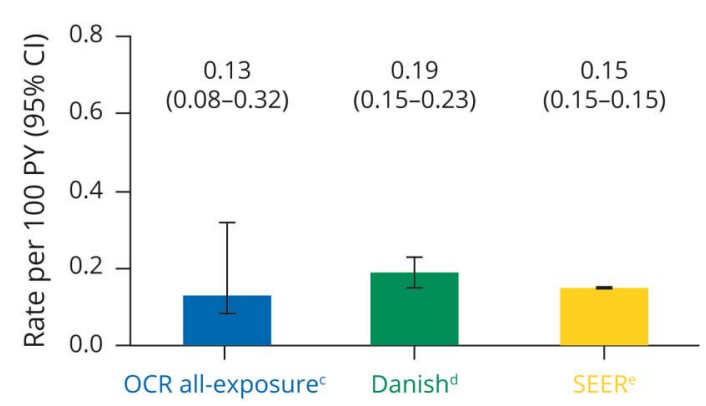

Standardized incidence ratio ${ }^{\mathrm{b}}$

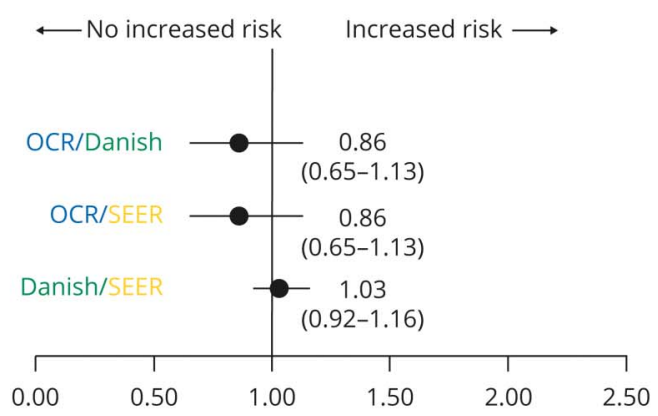

Standardized incidence ratio ${ }^{b}$

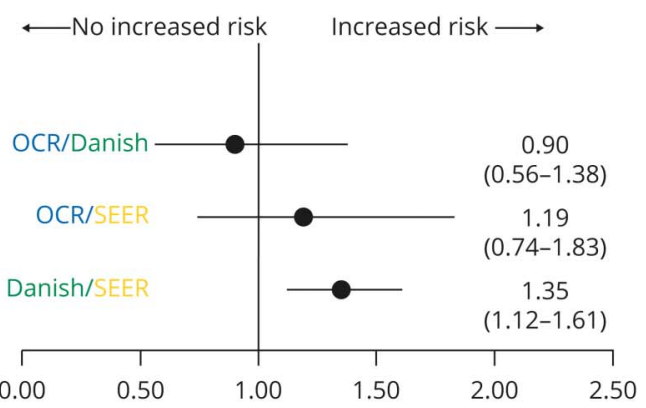

aStandardized incidence rates per 100 patient-years (PY) (95\% confidence interval [CI]) were derived using a direct standardization method that applies age-sex specific rates to the US population (2010 census), with restriction to the age range of the MS clinical trials (15-59 years). For all malignancies, cases of nonmelanoma skin cancer (NMSC) were excluded from the ocrelizumab (OCR) all-exposure population and from the Danish MS registry to allow a comparison with the SEER database. ${ }^{\text {b}}$ The standardized incidence ratio (SIR) (95\% CI for Poisson distribution) was calculated as observed number of events/ expected number of events. For "OCR-comparison" SIR, SEER database and the Danish MS registry were used as reference populations. For "Danishcomparison" SIR, SEER database was used as reference population. ' $O C R$ all-exposure population: data represent the follow-up of 5,680 patients covering a period of approximately 7 years (up to January 2020). dDanish MS registry: data represent the follow-up of approximately 10,000 patients from 1995 to $2015 .{ }^{44}$ ESEER database: data cover approximately 27.8\% of the US population (based on 2010 census) from 2000 to 2016 (available at: seer.cancer.gov).

confirmed cases of PML observed in OCR-treated patients were classified as carryover cases ${ }^{28}$ from natalizumab or fingolimod, except one case in a 78-year-old man with prior intermittent mild lymphopenia of unknown etiology, not previously treated with any other DMTs. ${ }^{29}$ Whereas PML develops almost exclusively in patients with a severely compromised immune system, ${ }^{30}$ anecdotal PML cases have been reported in individuals with minimal or nonapparent immunosuppression, including older patients, in whom ageassociated immunosenescence is identified as a risk factor. ${ }^{31,32}$

The selective effects of OCR on the immune system may provide an explanation as to why the rates of SIs remained low and stable over a period of up to 7 years. OCR showed a differential effect on innate and adaptive immune system components. The changes observed in neutrophil levels were mostly transient and appear to be within the range of biologic variability, with similar proportions of patients with neutropenia in the OCR (OPERA: 14.7\%, ORATORIO: $12.9 \%$ ) and the placebo arms (ORATORIO: $10.0 \%)$. Cases of serious neutropenia remained infrequent, were not treatment-limiting, and importantly, were not associated with an increased risk of SIs. These findings, together with the preserved counts of NK cells, suggest that OCR has limited effect on the innate immune system.

Regarding the adaptive immune system, a small initial decrease in median circulating lymphocyte counts was observed, but remained stable with continued treatment. This was likely driven by the rapid and sustained depletion of $\mathrm{CD} 20^{+} \mathrm{B}$ cells, the most relevant pharmacodynamic effect of OCR, but could in part occur by depletion of $\mathrm{CD} 3{ }^{+} \mathrm{CD} 20^{+}$cells, which represents $3 \%-5 \%$ of circulating $\mathrm{T}$ cells, ${ }^{33}$ and are susceptible to depletion by $\mathrm{OCR}^{34}$ Alternatively, B-cell depletion from lymphoid tissue might drive homeostatic changes in T-cell distribution between blood and lymph nodes. However, a highly diverse T-cell repertoire persists, suggesting that antigen presentation by $\mathrm{B}$ cells, which is essential for maintenance of T-cell-mediated adaptive immunity, is preserved. ${ }^{35}$ Moreover, by the end of the 7-year observation period, T-cell levels had returned to normal.

The reduction in serum Ig levels may be explained by the mechanism of action of OCR. However, at the dosing regimen of $600 \mathrm{mg}$ every 6 months, Ig levels remained within normal ranges for most patients even after 7 years of continued 
Table 2 Preexisting Humoral Immunity in the Phase 3 Studies

\begin{tabular}{|c|c|c|c|c|c|c|c|c|}
\hline & \multicolumn{4}{|c|}{ OPERA (pooled) } & \multicolumn{4}{|c|}{ ORATORIO } \\
\hline & \multicolumn{2}{|c|}{$\begin{array}{l}\text { IFN- } \beta-1 a \\
(\mathrm{n}=826)\end{array}$} & \multicolumn{2}{|c|}{$\begin{array}{l}\text { OCR } \\
(\mathrm{n}=825)\end{array}$} & \multicolumn{2}{|c|}{$\begin{array}{l}\text { Placebo } \\
(\mathrm{n}=239)\end{array}$} & \multicolumn{2}{|c|}{$\begin{array}{l}\text { OCR } \\
(n=486)\end{array}$} \\
\hline & BL & $\begin{array}{l}\text { Week } \\
96\end{array}$ & BL & $\begin{array}{l}\text { Week } \\
96\end{array}$ & BL & $\begin{array}{l}\text { Week } \\
120\end{array}$ & BL & $\begin{array}{l}\text { Week } \\
120\end{array}$ \\
\hline \multicolumn{9}{|l|}{ Patients with positive antibody titer at baseline and end of CTP, \% } \\
\hline Mumps virus & 94.1 & 92.7 & 93.6 & 91.8 & 92.8 & 92.7 & 92.9 & 92.7 \\
\hline Rubella virus & 87.9 & 90.8 & 89.0 & 88.7 & 90.7 & 92.3 & 93.1 & 92.5 \\
\hline Varicella-zoster virus & 95.5 & 97.2 & 95.5 & 95.0 & 96.4 & 99.3 & 96.1 & 95.3 \\
\hline $\begin{array}{l}\text { Change in absolute } S \text {. pneumoniae capsular polysaccharide titers from } \\
\text { baseline to end of CTP, mean (SD) antibody levels, } \mathrm{mg} / \mathrm{L}\end{array}$ & $\begin{array}{l}53.67 \\
(54.13)\end{array}$ & $\begin{array}{l}51.74 \\
(42.50)\end{array}$ & $\begin{array}{l}55.35 \\
(67.00)\end{array}$ & $\begin{array}{l}54.06 \\
(80.98)\end{array}$ & $\begin{array}{l}73.96 \\
(84.64)\end{array}$ & $\begin{array}{l}68.85 \\
(80.15)\end{array}$ & $\begin{array}{l}68.11 \\
(67.53)\end{array}$ & $\begin{array}{l}60.76 \\
(63.30)\end{array}$ \\
\hline
\end{tabular}

Abbreviations: $\mathrm{BL}=$ baseline; $\mathrm{CTP}=$ controlled treatment period; IFN = interferon; OCR = ocrelizumab.

$\mathrm{BL}$ is the patient's last observation prior to the initiation of the study drug. For OPERA 1 and OPERA 2 , antibody titers were collected at weeks $12,24,48,72$, and 96 postbaseline. Antibody titers were collected at week 120 only postbaseline in ORATORIO.

treatment. Most patients reaching IgG levels below the LLN were found to be in the lowest baseline IgG quartile, although the relative reduction observed over time was similar across quartiles. ${ }^{36}$ Baseline age, body mass index, Expanded Disability Status Scale score, disease duration, and treatment with previous DMTs were, overall, similar across quartiles, whereas higher IgG levels were observed in women, ${ }^{36}$ consistent with well-known biological sex differences. ${ }^{37}$ An apparent association between decreased levels of IgG and rates of SIs was observed, but the types, severity, duration, and outcomes of these infections were similar to the overall population treated with OCR, and to the general MS population. It should be noted that other risk factors, such as age, body mass index, comorbidities, disability level, and previous treatment with other DMTs ${ }^{24,25,38}$ may influence the risk of SIs; the relative importance of these factors in the OCRtreated population will be reported elsewhere (manuscript under preparation).

Despite observed reductions in serum IgG levels, preexisting specific humoral immunity to certain common viral (mumps, rubella, varicella zoster viruses) and bacterial (S. pneumoniae) antigens was preserved over a period of approximately 2 years. The effects of OCR on humoral responses against clinically relevant vaccines were also assessed in the VELOCE study, showing that patients treated with OCR mounted a humoral response, although attenuated, to clinically relevant vaccines and a neoantigen, despite peripheral B-cell depletion. ${ }^{39}$ This may be explained in part by the fact that tissue-resident memory B cells, which are abundant in the spleen and other tissues, may not be fully depleted. ${ }^{40}$ A recent analysis of $\mathrm{B}$ lineage cells in tissues of healthy organ donors revealed tissuespecific differences and discordance between blood and tissues; blood levels did not appear to predict memory B-cell compartments in terms of frequency and Ig isotype in any of the tissues and that blood was not in equilibrium with the spleen. $^{41}$
Vaccination is one important way of reducing the risk of some infectious diseases. Recommendations may vary across countries, but in line with the latest American Academy of Neurology guidance, ${ }^{42}$ patients who require vaccination should complete their immunization with live or nonlive vaccines at least 4 and 2 weeks prior to initiation of OCR, respectively. ${ }^{8}$ Such time frames allow for the humoral response to occur, while observing safety considerations related to live vaccines. Nonlive vaccines (e.g., annual seasonal influenza) are also recommended in patients while on treatment with OCR, and ideally should be administered 4 weeks prior to the next scheduled dose, similar to recommendations available for other B-cell-depleting therapies. ${ }^{43}$ For nonlive vaccines that require 2 doses, such as the coronavirus disease 2019 (COVID-19) vaccine, the first dose should be administered around 12 weeks following the prior OCR infusion and the second dose given 4 weeks (latest) prior to the next scheduled OCR infusion, as per the VELOCE study. ${ }^{39}$

Analyses of malignancy and female breast cancer rates in the overall clinical program and additional postmarketing data do not indicate an increased risk compared with matched reference MS and general populations ${ }^{44,45}$ or a time-dependent exposure effect. These results are consistent with findings from other anti-CD20 therapies such as rituximab, which show no predisposition to second primary malignancies. ${ }^{46}$ Considering the inherent limitations of a clinical trial population in identifying rare events, and the potential underreporting in the postmarketing setting, more data are required. Postapproval safety studies (CONFIDENCE, MANUSCRIPT, VERISMO) that will follow approximately 9,000 newly OCR-treated patients are ongoing to inform longterm safety and, specifically, the potential risk of malignancies. ${ }^{47}$

Finally, in contrast to other humanized monoclonal antibodies used in the treatment of $\mathrm{MS}^{48,49}$ and similar to fully human monoclonal antibodies, ${ }^{50}$ immunogenicity observed with OCR was infrequent and mostly transient, thereby supporting its long-term use. 
This integrated general safety analysis has some limitations. The nature of the OLEs and phase $3 \mathrm{~b}$ studies limits conclusions due to the absence of control groups. Whereas the stability of the overall rates and patterns of AEs in the OLE period relative to the CTP provides a comparative reference, response bias due to underreporting cannot be excluded. For AEs such as malignancies, fatal outcomes, and SIs, the use of data from MS registries and postmarketing sources allows further contextualization of the incidence rates, although selection bias may be present given possible differences in populations. Moreover, potential underreporting in the postmarketing setting could lead to further bias; however, the more severe cases of AEs are often reported. In studies with a long follow-up period, attrition bias is also a recognized limitation, but rates of discontinuation remain infrequent and over $90 \%$ of patients who completed the CTPs entered the long-term extensions. ${ }^{6,7}$

In conclusion, these results suggest that continuous administration of OCR for up to 7 years is associated with a favorable and manageable safety profile. No new safety concerns have emerged in a heterogeneous MS population (in more recent clinical trials and real-world settings) that includes early treatment-naive patients with relapsingremitting multiple sclerosis, patients with RMS previously treated with other DMTs, and patients with active secondary progressive multiple sclerosis or PPMS who are older, are more disabled, and have a longer DMT history and higher number of comorbidities. Long-term follow-up and postlong-term treatment with OCR in increasing numbers of patients.

\section{Acknowledgment}

The authors thank Erwan Muros-Le Rouzic, MPH; Annette Sauter, PhD; Kocho Fitovski, MD; Steve Matsuoka, PharmD; Christian Mueller, PhD; and David Wormser, PhD, for their contributions to this work; and the patients, their families, and the investigators who participated in this trial. This research was funded by F. Hoffmann-La Roche Ltd, Basel, Switzerland. Heather Latimer of Articulate Science, UK, wrote the first draft of the manuscript based on input from the authors, which was funded by F. Hoffmann-La Roche Ltd. The authors had full editorial control of the manuscript and provided their final approval of all content. Statistical Analysis performed by: Kalpesh Prajapati, MSc, MPhil, IQVIA Solutions Inc., Amsterdam, the Netherlands.

\section{Study Funding}

This work was supported by financial support from F. Hoffmann-La Roche Ltd, Basel, Switzerland, for the study and publication of the manuscript.

\section{Disclosure} on scientific advisory boards for Alector, Annexon, Accure, and Molecular Stethoscope, and has received travel reimbursement marketing studies will continue to monitor the safety of

S.L. Hauser serves on the board of directors for Neurona and

and writing assistance from F. Hoffmann-La Roche Ltd and Novartis for CD20-related meetings and presentations. L. Kappos' institution (University Hospital Basel) received in the last 3 years and used exclusively for research support at the Department steering committee, advisory board, consultancy fees, and support of educational activities from Actelion, Allergan, Almirall, Baxalta, Bayer, Biogen, Celgene/Receptos, CSL-Behring, Desitin, Excemed, Eisai, Genzyme, Japan Tobacco, Merck, Minoryx, Novartis, Pfizer, F. Hoffmann-La Roche Ltd, Sanofi Aventis, Santhera, and Teva, and license fees for Neurostatus-UHB products; the Research of MS Center in Basel has been supported by grants from Bayer, Biogen, Novartis, the Swiss MS Society, the Swiss National Research Foundation, Innosuisse, the European Union, and Roche Research Foundations. X. Montalban received speaking honoraria and travel expenses for scientific meetings and has been a steering committee member of clinical trials or participated in advisory boards of clinical trials in the past 3 years with Actelion, Alexion, Bayer, Biogen, Celgene, EMD Serono, EXCEMED, Genzyme, MedDay, Merck, MSIF, Nervgen, NMSS, Novartis, Roche, Sanofi-Genzyme, Teva Pharmaceutical, and TG Therapeutics. L. Craveiro is an employee and shareholder of F. Hoffmann-La Roche Ltd. C. Chognot is an employee of F. Hoffmann-La Roche Ltd. R. Hughes was an employee of F. Hoffmann-La Roche Ltd during completion of the work related to this manuscript. H. Koendgen was an employee and shareholder of F. Hoffmann-La Roche Ltd during completion of the work related to this manuscript. N. Pasquarelli is an employee and shareholder of F. Hoffmann-La Roche Ltd. A. Pradhan is an employee of Genentech, Inc. K. Prajapati has received consulting fees from F. Hoffmann-La Roche Ltd for statistical assistance and is an employee of IQVIA Solutions Inc. J.S. Wolinsky has received personal compensation for consulting, serving on a scientific advisory board, speaking, or other activities with Avotres, Brainstorm Cell Therapeutics, Cleveland Clinic Foundation, EMD Serono, MedDay Pharmaceuticals, NervGen Pharma Corp., Novartis, Roche/Genentech, Sanofi Genzyme, and University of Alabama; royalties are received for outlicensed monoclonal antibodies through UTHealth from Millipore Corporation. Go to Neurology.org/ $\mathrm{N}$ for full disclosures.

\section{Publication History}

Received by Neurology January 15, 2021. Accepted in final form July 29, 2021.

Appendix Authors

\begin{tabular}{lll}
\hline Name & Location & Contribution \\
\hline $\begin{array}{l}\text { Stephen L. } \\
\text { Hauser, MD }\end{array}$ & $\begin{array}{l}\text { University of California, } \\
\text { San Francisco }\end{array}$ & $\begin{array}{l}\text { Designed and conceptualized } \\
\text { studies; reviewed the data; } \\
\text { drafted and revised the } \\
\text { manuscript content }\end{array}$ \\
\hline $\begin{array}{l}\text { Ludwig } \\
\text { Kappos, MD }\end{array}$ & $\begin{array}{l}\text { University Hospital } \\
\text { Basel, University of } \\
\text { Basel, Switzerland }\end{array}$ & $\begin{array}{l}\text { Designed and conceptualized } \\
\text { studies; reviewed the data; } \\
\text { drafted and revised the } \\
\text { manuscript content }\end{array}$ \\
\hline
\end{tabular}

Continued 
Appendix (continued)

\begin{tabular}{lll}
\hline Name & Location & Contribution \\
\hline Xavier & Vall d'Hebron University & Designed and conceptualized \\
Montalban, & Hospital, Barcelona, & $\begin{array}{l}\text { studies; reviewed the data; } \\
\text { drafted and revised the } \\
\text { MD, PhD, MBA }\end{array}$ \\
& Spain & $\begin{array}{l}\text { manuscript content } \\
\end{array}$
\end{tabular}

Licinio F. Hoffmann-La Roche Designed and conceptualized

Craveiro, MD, Ltd, Basel, Switzerland CONSONANCE study; reviewed PhD

the data; drafted and revised the manuscript content

Cathy F. Hoffmann-La Roche Designed and conceptualized

Chognot, PhD Ltd, Basel, Switzerland VELOCE study; reviewed the data; drafted and revised the manuscript content

Richard F. Hoffmann-La Roche Reviewed the data; drafted and Hughes, MD Ltd, Basel, Switzerland revised the manuscript content

\begin{tabular}{lll}
\hline Harold & F. Hoffmann-La Roche & Reviewed the data; drafted and \\
Koendgen, & Ltd, Basel, Switzerland & revised the manuscript content
\end{tabular}

MD, PhD

Noemi F. Hoffmann-La Roche Reviewed the data; drafted and

Pasquarelli, Ltd, Basel, Switzerland revised the manuscript content

PhD, MSc

Ashish Genentech, Inc., South Designed and conceptualized

Pradhan, MD San Francisco, CA CHORDS study; reviewed the data; drafted and revised the manuscript content

\begin{tabular}{lll}
\hline $\begin{array}{l}\text { Kalpesh } \\
\text { Prajapati, } \\
\text { MSc, MPhil }\end{array}$ & $\begin{array}{l}\text { IQVIA Solutions Inc., } \\
\text { Amsterdam, the } \\
\text { Netherlands }\end{array}$ & $\begin{array}{l}\text { Analyzed the data; drafted and } \\
\text { revised the manuscript content }\end{array}$ \\
\hline $\begin{array}{l}\text { Jerry S. } \\
\text { Wolinsky, MD }\end{array}$ & $\begin{array}{l}\text { McGovern Medical } \\
\text { School, UTHealth, Texas }\end{array}$ & $\begin{array}{l}\text { Designed and conceptualized } \\
\text { studies; reviewed the data; } \\
\text { drafted and revised the } \\
\text { manuscript content }\end{array}$ \\
\end{tabular}

\section{References}

1. DiLillo DJ, Hamaguchi Y, Ueda Y, et al. Maintenance of long-lived plasma cells and serological memory despite mature and memory B cell depletion during CD20 immunotherapy in mice. J Immunol. 2008;180(1):361-371.

2. Klein C, Lammens A, Schäfer W, et al. Epitope interactions of monoclonal antibodies targeting CD20 and their relationship to functional properties. MAbs. 2013;5(1):22-33.

3. Kappos L, Li D, Calabresi PA, et al. Ocrelizumab in relapsing-remitting multiple sclerosis: a phase 2, randomised, placebo-controlled, multicentre trial. Lancet. 2011; 378(19805):1779-1787.

4. Hauser SL, Bar-Or A, Comi G, et al. Ocrelizumab versus interferon beta-1a in relapsing multiple sclerosis. N Engl J Med. 2017;376:221-234.

5. Montalban X, Hauser SL, Kappos L, et al. Ocrelizumab versus placebo in primary progressive multiple sclerosis. N Engl J Med. 2017;376(13):209-220.

6. Giovannoni G, Kappos L, de Seze J, et al. Long-term reduction of relapse rate and 48week confirmed disability progression after 6.5 years of ocrelizumab treatment in patients with RMS. Presented at the 8th Joint ACTRIMS-ECTRIMS Meeting; 2020; MSVirtual2020.

7. Wolinsky J, Vermersch P, Hartung H-P, et al. Sustained reduction in 48-week confirmed disability progression in patients with PPMS treated with ocrelizumab in the ORATORIO OLE: 7-year follow-up. Presented at the 8th Joint ACTRIMSECTRIMS Meeting; 2020; MSVirtual2020.

8. Genentech. Ocrevus (Ocrelizumab) [Full Prescribing Information] [online]. Accessed January 20, 2020. gene.com/download/pdf/ocrevus prescribing.pdf

9. Mayer L, Kappos L, Racke MK, et al. Ocrelizumab infusion experience in patients with relapsing and primary progressive multiple sclerosis: results from the phase 3 randomized OPERA I, OPERA II, and ORATORIO studies. Mult Scler Relat Disord. 2019;30(1):236-243.

10. Matthias M, Stefanie F, Patricia $\mathrm{H}$, et al. Preserved antigen-specific immune response in patients with multiple sclerosis responding to IFN $\beta$-therapy. PLoS One. 2013; 8(111):e78532.

11. Berger JR, Aksamit AJ, Clifford DB, et al. PML diagnostic criteria: consensus statement from the AAN Neuroinfectious Disease Section. Neurology. 2013;80:1430-1438.

12. Clifford D, Gass A, Richert N, et al. Cases reported as progressive multifocal leukoencephalopathy in ocrelizumab-treated patients with multiple sclerosis. Presented at the European Committee for Treatment and Research in Multiple Sclerosis (ECTRIMS); 2019.

13. Kingwell E, Bajdik C, Phillips N, et al. Cancer risk in multiple sclerosis: findings from British Columbia, Canada. Brain. 2012;135(pt 10):2973-2979.

14. Yang XR, Chang-Claude J, Goode EL, et al. Associations of breast cancer risk factors with tumor subtypes: a pooled analysis from the Breast Cancer Association Consortium studies. J Natl Cancer Inst. 2011;103(13):250-263.

15. Butzkueven H, Spelman T, Ozakbas S, et al. Real-world experience with ocrelizumab in the MSBase Registry. Presented at the 8th Joint ACTRIMS-ECTRIMS Meeting, 2020; MSVirtual2020.

16. Engmann N, Sheinson D, Ng C, Julian L, Pardo G. Persistence and adherence to ocrelizumab compared with other disease-modifying therapies for multiple sclerosis for up to 18 months in the US. Presented at the 8th Joint ACTRIMS-ECTRIMS Meeting; 2020; MSVirtual2020.

17. Meuth S, Buttmann M, Weber M, et al. Treatment persistence and adherence to ocrelizumab in the real-world setting: an ad-hoc analysis of the CONFIDENCE study. Presented at the 8th Joint ACTRIMS-ECTRIMS Meeting; 2020; MSVirtual2020.

18. Leray E, Vukusic S, Debouverie M, et al. Excess mortality in patients with multiple sclerosis starts at 20 years from clinical onset: data from a large-scale French obser vational study. PLoS One. 2015;10(:e0132033.

19. Goodin DS, Corwin M, Kaufman D, et al. Causes of death among commercially insured multiple sclerosis patients in the United States. PLoS One. 2014;9(18): e105207.

20. Vollmer T, Cohen J, Alverez E, et al. Safety results of administering ocrelizumab per a shorter infusion protocol in patients with primary progressive and relapsing multiple sclerosis. Mult Scler Relat Disord. 2020;46(1):102454.

21. Bermel R, Waubant E, Pardo G, et al. Evaluation of shorter infusion times for ocrelizumab treatment in an extension substudy of the phase IIIb CHORDS trial. Presented at the 35th Congress of the European Committee for Treatment and Research in Multiple Sclerosis (ECTRIMS); 2019; Stockholm, Sweden.

22. Hartung HP, Berger T, Bermel RA, et al. Shorter infusion time of ocrelizumab: results from the randomized, double-blind ENSEMBLE PLUS substudy in patients with relapsing-remitting multiple sclerosis. Mult Scler Relat Disord. 2020;46(1):102492.

23. Sehn LH, Donaldson J, Filewich A, et al. Rapid infusion rituximab in combination with corticosteroid-containing chemotherapy or as maintenance therapy is well tolerated and can safely be delivered in the community setting. Blood. 2007;109(110): 4171-4173.

24. Wijnands JM, Kingwell E, Zhu F, et al. Infection-related health care utilization among people with and without multiple sclerosis. Mult Scler. 2017;23(111):1506-1516.

25. Nelson RE, Xie Y, DuVall SL, et al. Multiple sclerosis and risk of infection-related hospitalization and death in US veterans. Int J MS Care. 2015;17(15):221-230.

26. Castelo-Branco A, Chiesa F, Conte S, et al. Infections in patients with multiple sclerosis: a national cohort study in Sweden. Mult Scler Relat Disord. 2020;45(1) 102420.

27. Persson R, Lee S, Ulcickas Yood M, et al. Infections in patients diagnosed with multiple sclerosis: a multi-database study. Mult Scler Relat Disord. 2020;41(1):101982.

28. Giovannoni G, Marta M, Davis A, Turner B, Gnanapavan S, Schmierer K. Switching patients at high risk of PML from natalizumab to another disease-modifying therapy. Pract Neurol. 2016;16(15):389-393.

29. Sul J, Patel A, Gordon ML, et al. Progressive multifocal leukoencephalopathy in a patient on ocrelizumab monotherapy. Neurology. 2020;94(suppl 15):4875.

30. Major EO, Yousry TA, Clifford DB. Pathogenesis of progressive multifocal leukoencephalopathy and risks associated with treatments for multiple sclerosis: a decade of lessons learned. Lancet Neurol. 2018;17(15):467-480.

31. Gheuens S, Pierone G, Peeters P, Koralnik IJ. Progressive multifocal leukoencephalopathy in individuals with minimal or occult immunosuppression. J Neurol Neurosurg Psychiatry. 2010;81(13):247-254.

32. Mills EA, Mao-Draayer Y. Aging and lymphocyte changes by immunomodulatory therapies impact PML risk in multiple sclerosis patients. Mult Scler. 2018;24(18) 1014-1022.

33. Schuh E, Berer K, Mulazzani M, et al. Features of human CD3+CD20+ T cells. J Immunol. 2016;197(14):1111-1117.

34. Gingele S, Jacobus TL, Konen FF, et al. Ocrelizumab depletes $\mathrm{CD} 20^{+} \mathrm{T}$ cells in multiple sclerosis patients. Cells. 2018;8(1):12.

35. Laurent $\mathrm{S}$, Michel B, Wu H, et al. Effect of ocrelizumab on B- and T-cell immune repertoires in patients with relapsing MS: a longitudinal IIT/substudy of the OPERA trial. Presented at the 7th Joint European Committee for Treatment and Research in Multiple Sclerosis (ECTRIMS) and Americas Committee for Treatment and Research in Multiple Sclerosis (ACTRIMS); 2017; Paris, France.

36. Bar-Or A, Bermel R, Weber MS, et al. Serum Ig levels and risk of serious infections by baseline Ig quartile in the pivotal phase III trials and open label extensions of ocrelizumab in multiple sclerosis. Presented at the 72nd Annual Meeting of the American Academy of Neurology (AAN); 2020; Virtual.

37. Ruggieri A, Anticoli S, D'Ambrosio A, et al. The influence of sex and gender on immunity, infection and vaccination. Ann Ist Super Sanità. 2016;52(12):198-204.

38. Luna G, Alping P, Burman J, et al. Infection risks among patients with multiple sclerosis treated with fingolimod, natalizumab, rituximab, and injectable therapies. JAMA Neurol. 2020;77(12):184-191.

39. Bar-Or A, Calkwood JC, Chognot C, et al. Effect of ocrelizumab on vaccine responses in patients with multiple sclerosis: the VELOCE study. Neurology. 2020;95(114) e1999-e2008

40. Gong $\mathrm{Q}, \mathrm{Ou} \mathrm{Q}, \mathrm{Ye} \mathrm{S}$, et al. Importance of cellular microenvironment and circulatory dynamics in B cell immunotherapy. J Immunol. 2005;174(12):817-826. 
41. Weisel NM, Weisel FJ, Farber DL, et al. Comprehensive analyses of B-cell compartments across the human body reveal novel subsets and a gut-resident memory phenotype. Blood. 2020;136(124):2774-2785.

42. Farez MF, Correale J, Armstrong MJ, et al. Practice guideline update summary: vaccine-preventable infections and immunization in multiple sclerosis: report of the Guideline Development, Dissemination, and Implementation Subcommittee of the American Academy of Neurology. Neurology. 2019;93(113):584-594.

43. Furer V, Rondaan C, Heijstek MW, et al. 2019 Update of EULAR recommendations for vaccination in adult patients with autoimmune inflammatory rheumatic diseases. Ann Rheum Dis. 2020;79(1):39-52.

44. Nørgaard M, Veres K, Didden EM, Wormser D, Magyari M. Multiple sclerosis and cancer incidence: a Danish nationwide cohort study. Mult Scler Relat Disord. 2019; 28(1):81-85.

45. National Institutes of Health (NIH). Overview of the SEER program [online]. Accessed January 2, 2020. seer.cancer.gov/about/overview.html
46. Fleury I, Chevret S, Pfreundschuh M, et al. Rituximab and risk of second primary malignancies in patients with non-Hodgkin lymphoma: a systematic review and metaanalysis. Ann Oncol. 2016;27(13):390-397.

47. Dirks P, Zingler V, Leemhuis J, et al. Design of a non-interventional post-marketing study to assess the long-term safety and effectiveness of ocrelizumab in German real world multiple sclerosis cohorts: the Confidence study protocol. BMC Neurol. 2020; 20(1):95.

48. Baker D, Ali L, Saxena G, et al. The irony of humanization: alemtuzumab, the first, but one of the most immunogenic, humanized monoclonal antibodies. Front Immunol. 2020;11(1):124.

49. Vennegoor A, Rispens T, Strijbis EM, et al. Clinical relevance of serum natalizumab concentration and anti-natalizumab antibodies in multiple sclerosis. Mult Scler. 2013; 19(5):593-600.

50. Hauser SL, Bar-Or A, Cohen JA, et al. Ofatumumab versus teriflunomide in multiple sclerosis. N Engl J Med. 2020;383(6):546-557. 


\section{Neurology}

\section{Safety of Ocrelizumab in Patients With Relapsing and Primary Progressive Multiple Sclerosis}

Stephen L. Hauser, Ludwig Kappos, Xavier Montalban, et al.

Neurology 2021;97;e1546-e1559 Published Online before print September 2, 2021

DOI 10.1212/WNL.0000000000012700

This information is current as of September 2, 2021

Neurology ${ }^{\circledR}$ is the official journal of the American Academy of Neurology. Published continuously since 1951, it is now a weekly with 48 issues per year. Copyright Copyright (C) 2021 The Author(s). Published by Wolters Kluwer Health, Inc. on behalf of the American Academy of Neurology.. All rights reserved. Print ISSN: 0028-3878. Online ISSN: 1526-632X.

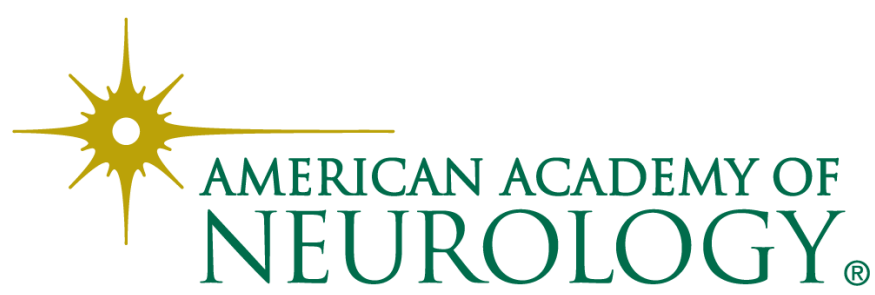




\section{Updated Information \& Services}

References

Citations

Subspecialty Collections

Permissions \& Licensing

\section{Reprints}

including high resolution figures, can be found at: http://n.neurology.org/content/97/16/e1546.full

This article cites 39 articles, 10 of which you can access for free at: http://n.neurology.org/content/97/16/e1546.full\#ref-list-1

This article has been cited by 3 HighWire-hosted articles: http://n.neurology.org/content/97/16/e1546.full\#\#otherarticles

This article, along with others on similar topics, appears in the following collection(s):

All Clinical Neurology

http://n.neurology.org/cgi/collection/all_clinical_neurology All Clinical trials

http://n.neurology.org/cgi/collection/all_clinical_trials

\section{Class II}

http://n.neurology.org/cgi/collection/class_ii

Medical care

http://n.neurology.org/cgi/collection/medical_care

Multiple sclerosis

http://n.neurology.org/cgi/collection/multiple_sclerosis

Patient safety

http://n.neurology.org/cgi/collection/patient_safety

Information about reproducing this article in parts (figures,tables) or in its entirety can be found online at:

http://www.neurology.org/about/about_the_journal\#permissions

Information about ordering reprints can be found online:

http://n.neurology.org/subscribers/advertise

Neurology ${ }^{\circledR}$ is the official journal of the American Academy of Neurology. Published continuously since 1951, it is now a weekly with 48 issues per year. Copyright Copyright ( 2021 The Author(s). Published by Wolters Kluwer Health, Inc. on behalf of the American Academy of Neurology.. All rights reserved. Print ISSN: 0028-3878. Online ISSN: 1526-632X.

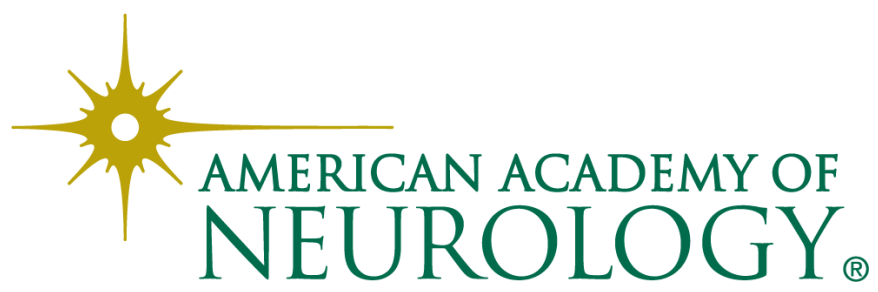

